\section{(2) OPEN ACCESS}

\title{
Heart failure medication dosage and survival in women and men seen at outpatient clinics
}

\author{
Sophie Heleen Bots (1) , ${ }^{1} \mathrm{~N}$ Charlotte Onland-Moret, ${ }^{2}$ Igor I Tulevski, ${ }^{3}$ \\ Pim van der Harst, ${ }^{4}$ Maarten J M Cramer, ${ }^{4}$ Folkert W Asselbergs, ${ }^{4,5,6}$ \\ G Aernout Somsen, ${ }^{3}$ Hester M den Ruijter (1) ${ }^{1}$
}

- Additional supplemental material is published online only. To view, please visit the journal online (http://dx.doi. org/10.1136/heartinl-2021319229).

For numbered affiliations see end of article.

\section{Correspondence to}

Prof. dr. ir. Hester M den Ruijter, Utrecht University, Utrecht 3508 TC, The Netherlands; H.M.denRuijter-2@umcutrecht. $\mathrm{nl}$

SHB and NCO-M are joint first authors.

Received 20 February 2021 Accepted 9 June 2021 Published Online First 14 July 2021

\section{Linked}

- http://dx.doi.org/10.1136/ heartjnl-2021-319831

Check for updates

(c) Author(s) (or their employer(s)) 2021. Re-use permitted under CC BY-NC. No commercial re-use. See rights and permissions. Published by BMJ.

To cite: Bots $\mathrm{SH}$, OnlandMoret NC, Tulevski II, et al. Heart 2021;107:1748-1755.

\section{ABSTRACT}

Objective Women with heart failure with reduced ejection fraction (HFrEF) may reach optimal treatment effect at half of the guideline-recommended medication dose. This study investigates prescription practice and its relation with survival of patients with $\mathrm{HF}$ in daily care. Methods Electronic health record data from 13 Dutch outpatient cardiology clinics were extracted for $\mathrm{HF}$ receiving at least one guideline-recommended $\mathrm{HF}$ medication. Dose changes over consecutive prescriptions were modelled using natural cubic splines. Inverse probability-weighted Cox regression was used to assess the relationship between dose (reference $\geq 50 \%$ target dose) and all-cause mortality.

Results The study population comprised 561 women (29\% HFrEF (ejection fraction $(E F)<40 \%$ ), 49\% heart failure with preserved ejection fraction $(\mathrm{EF} \geq 50 \%)$; $\mathrm{HFpEF}$ and 615 men (47\% and $25 \%$, respectively). During a median follow-up of 3.7 years, 252 patients died (48\% women; $167 \mathrm{HFrEF}, 84 \mathrm{HFpEF})$. Nine hundred thirty-four patients ( $46 \%$ women) received ACE inhibitors (ACEIs) or angiotensin receptor blockers (ARBs), 795 (48\% women) beta blockers and 178 (42\% women) mineralocorticoid receptor antagonists (MRAs). In both sexes, the mean target dose across prescriptions was $50 \%$ for ACEl/ARBs and beta blockers, and 100\% for MRAs. ACEI/ARB dose of $<50 \%$ was associated with lower mortality in women but not in men with HFrEF. This was not seen in patients with HFpEF. Beta-blocker dose was not associated with all-cause mortality.

Conclusion Patients with HF seen in outpatient

cardiology clinics receive half of the guidelinerecommended medication dose. Lower ACEI/ARB dose was associated with improved survival in women with HFrEF. These results underscore the importance of (re) defining optimal medical therapy for women with HFrEF.

\section{INTRODUCTION}

Heart failure (HF) affects 26 million people worldwide,${ }^{1}$ half of which are women. ${ }^{2}$ Despite known sex differences in both its presentation ${ }^{3}$ and response to drug therapy, ${ }^{4} \mathrm{HF}$ guidelines recommend the same target doses for women and men. ${ }^{5}$ This is debated because women are under-represented in HF trials and sex-stratified data remain scarce. ${ }^{2}$ Efforts to increase the number of women in trials have had limited success, ${ }^{6}$ possibly because inclusion criteria favour the male pattern of disease. Inclusion criteria based on age, ejection fraction
(EF) and brain natriuretric peptide levels that do not consider sex differences disproportionally exclude women. ${ }^{7-9}$ Often, HF trials also exclude elderly or multimorbid patients, resulting in study populations healthier than 'real-world' patients. ${ }^{10}$ It remains unclear how findings from HF trials and recommendations based on these trials translate to daily care.

Two heart failure with reduced ejection fraction (HFrEF) cohorts challenged current recommendations by showing that women receiving $50 \%$ of the guideline-recommended dose for ACE inhibitors (ACEIs)/angiotensin-receptor blockers (ARBs) or beta blockers had better survival and fewer HF hospitalisations during follow-up than women on higher doses, whereas in men, prognosis improved with increasing dose. ${ }^{11}$ Dutch registry data showed that women with HFrEF often already receive lower doses than guideline-recommended in daily care. ${ }^{12}$ Medication dosage in women with HF may additionally be complicated because women more often present with heart failure with preserved ejection fraction $(\mathrm{HFpEF})^{7}$ for which effective treatments and dosage information are lacking. ${ }^{5}$ We used routine care data from Dutch outpatient cardiology clinics to describe current dosage practices in a heterogeneous HF population and investigate the association between medication dosage and survival across sexes and HF subtypes.

\section{METHODS}

\section{Study population}

The Cardiology Centers of the Netherlands (CCN) database contains routine clinical care data from 109151 patients referred for cardiac workup by their general practitioner (GP) on suspicion of cardiac disease between 2007 and 2018. During the first visit, information was collected on anthropometric measurements, cardiovascular risk factors, medical history, comorbidities and medication use. All patients underwent transthoracic echocardiography.

For the current study, all patients with a new HF diagnosis registered in the clinical care database within the 2 weeks prior to and including the baseline visit ('de novo' HF) were included. As all patients referred to $\mathrm{CCN}$ are seen within 2 weeks, any diagnosis within this period can be considered de novo. Patients with known HF were excluded to minimise survival bias. 


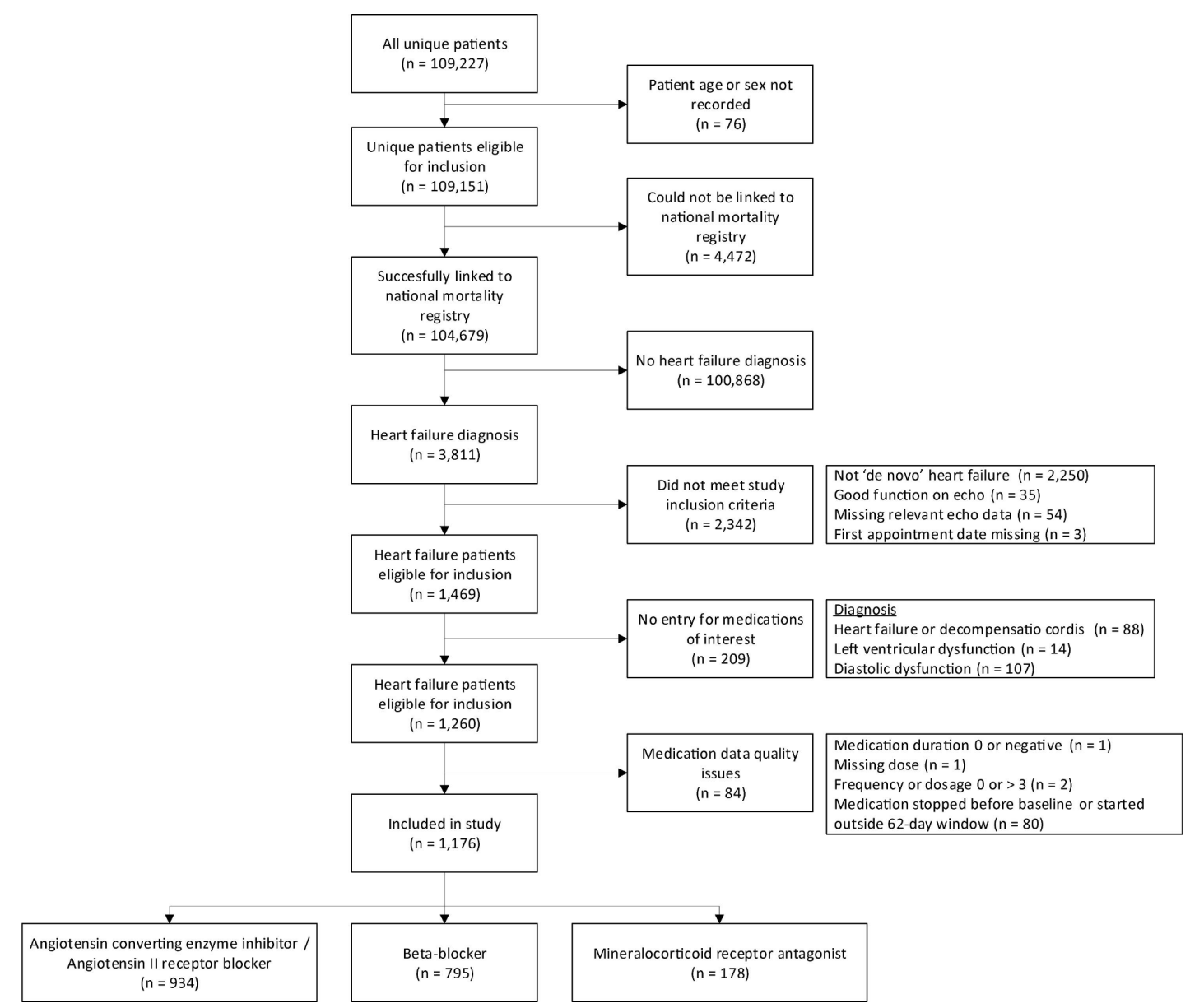

Figure 1 Flowchart of the study population selection.

HF was defined as either (1) a diagnosis of HF or decompensatio cordis registered by the cardiologist, or (2) a diagnosis of left ventricular (LV) dysfunction or diastolic dysfunction registered by the cardiologist that was verified using the LV systolic or diastolic function reported by the echocardiographist, respectively. Patients for whom the LV function could not be verified were excluded. HF was divided into reduced $(<40 \%)$, mid-range (40\%-50\%) and preserved EF ( $\geq 50 \%)$ subtypes. $^{5}$

\section{Guideline-recommended HF medication and target dose}

Medication groups were defined based on the 2016 ESC HF guideline $^{5}$ and included ACEI/ARBs, beta blockers and mineralocorticoid receptor antagonists (MRAs). Medication prescriptions were identified with pattern matching based on a combination of generic compound names and brand names. Medication dose was extracted from text fields using pattern matching and multiplied by daily frequency and dosage to obtain the daily dose per prescription.

Target doses were taken from the 2016 guideline, ${ }^{5}$ from literature $^{11}$ or calculated using conversion tables. ${ }^{13-15}$ To enable comparison between medication groups, daily dose was converted to percentage of target dose. Percentage of target dose was used both as continuous and dichotomous variables with levels of $<50 \%$ and $\geq 50 \%$, depending on the analysis. The dichotomous variable was chosen based on the hypothesis that women have a better prognosis at $<50 \%$ of target dose.

Baseline HF medication was defined as the first prescription for each medication category that was prescribed within the period 31 days prior to and 31 days after the patient's CCN visit. First prescriptions that started either before or after the relevant time window, prescriptions that ended before the CCN visit, one-off prescriptions and prescriptions with data entry errors were excluded. Prescriptions started more than 31 days prior to the CCN visit were categorised as medication history. Medication use was tracked over time within the $\mathrm{CCN}$ database, including dose changes. To show dosage over time, all prescriptions registered after the baseline HF medication prescription were numbered in order of prescription date and the dose was converted to percentage of target dose as described earlier.

\section{Outcomes}

Passive follow-up for all-cause mortality was available for $95.9 \%$ of the study population via linkage to the national causes of death registry from Statistics Netherlands. This registry continuously collects all official cause of death reports submitted by medical doctors and coroners in the Netherlands and is updated quarterly and yearly. The cause of death is coded using the International Classification of Diseases and Related Health Problems, Edition 10. For the current analyses, all-cause mortality was available until 12 February 2020. Follow-up time for patients who were still alive was censored at 12 February 2020.

\section{Statistical analyses}

Continuous variables were reported as mean (SD) or median (IQR). Categorical variables were reported as number and percentage. Sex-specific dosing patterns were evaluated by plotting the percentage of target dose prescribed against the 
Table 1 Baseline characteristics of the study population

\begin{tabular}{|c|c|c|}
\hline & $\begin{array}{l}\text { Women } \\
(\mathrm{n}=561)\end{array}$ & $\begin{array}{l}\text { Men } \\
(n=615)\end{array}$ \\
\hline \multicolumn{3}{|c|}{ General (mean (SD) or median (IQR)) } \\
\hline Age (years) & $71(12)$ & $67(12)$ \\
\hline \multicolumn{3}{|l|}{ Ethnicity, n (\%) } \\
\hline Native Dutch & $471(84.0)$ & $478(77.7)$ \\
\hline First-generation immigrant & $54(9.6)$ & $88(14.3)$ \\
\hline $\begin{array}{l}\text { Second-generation } \\
\text { immigrant }\end{array}$ & $36(6.4)$ & $49(8.0)$ \\
\hline Income $(€)$ & $17,435(10,733-26,391)$ & $32,351(18,545-46,647)$ \\
\hline Current smoker, n (\%) & $158(28.2)$ & $167(27.2)$ \\
\hline \multicolumn{3}{|l|}{ Ejection fraction, $n(\%)$} \\
\hline$<40 \%$ & $162(28.9)$ & $291(47.3)$ \\
\hline $40 \%-49 \%$ & $86(15.3)$ & $123(20.0)$ \\
\hline$\geq 50 \%$ & $272(48.5)$ & $155(25.2)$ \\
\hline not recorded & $41(7.3)$ & $46(7.5)$ \\
\hline \multicolumn{3}{|c|}{ Medical history and comorbidities, $\mathrm{n}(\%)$} \\
\hline Hypertension & $309(55.1)$ & $274(44.6)$ \\
\hline Diabetes mellitus & $74(13.2)$ & $122(19.8)$ \\
\hline Coronary heart disease & $42(7.5)$ & $118(19.2)$ \\
\hline Cerebrovascular disease & $47(8.4)$ & $52(8.5)$ \\
\hline Cardiovascular intervention & $47(8.4)$ & $140(22.8)$ \\
\hline Arrhythmia & $116(20.7)$ & $154(25.0)$ \\
\hline Valvular heart disease & $50(8.9)$ & $62(10.1)$ \\
\hline \multicolumn{3}{|c|}{ Clinical measures (mean (SD) or median (IQR)) } \\
\hline Body Mass Index $\left(\mathrm{kg} / \mathrm{m}^{2}\right)$ & $27.5(5.6)$ & $28.1(4.7)$ \\
\hline $\begin{array}{l}\text { Systolic blood pressure }(\mathrm{mm} \\
\mathrm{Hg})\end{array}$ & $150(26)$ & $146(24)$ \\
\hline $\begin{array}{l}\text { Diastolic blood pressure } \\
(\mathrm{mm} \mathrm{Hg})\end{array}$ & $88(14)$ & $88(15)$ \\
\hline Total cholesterol (mmol/L) & $5.02(1.13)$ & $4.55(1.13)$ \\
\hline Triglycerides (mmol/L) & $1.40(1.00-2.10)$ & $1.60[(.10-2.20)$ \\
\hline $\begin{array}{l}\text { Estimated glomerular } \\
\text { filtration rate }(\mathrm{mL} / \mathrm{min} / 1.73 \\
\left.\mathrm{m}^{2}\right)\end{array}$ & $65(27)$ & $66(28)$ \\
\hline \multicolumn{3}{|c|}{ Medication prescribed at baseline, $\mathrm{n}(\%)$} \\
\hline ACEI/ARB & $428(76.3)$ & $506(82.3)$ \\
\hline Beta blocker & $381(67.9)$ & $414(67.3)$ \\
\hline $\begin{array}{l}\text { Mineralocorticoid receptor } \\
\text { antagonist }\end{array}$ & $74(13.2)$ & $104(16.9)$ \\
\hline Diuretic & $325(57.9)$ & $314(51.1)$ \\
\hline \multicolumn{3}{|c|}{ Number of medication classes prescribed } \\
\hline 1 & $261(46.5)$ & $251(41.1)$ \\
\hline 2 & $251(44.7)$ & $286(46.5)$ \\
\hline 3 & $49(8.7)$ & $76(12.4)$ \\
\hline
\end{tabular}

ACEl, ACE inhibitor; ARB, angiotensin-receptor blocker.

consecutive number of prescriptions within each medication group. A natural cubic spline with three knots was used to visualise trends. The sex-specific relationship between percentage of target dose at baseline and all-cause mortality was evaluated using Cox regression in the whole population and stratified by HF subtype, with the $\geq 50 \%$ target dose as reference group. We used the product of target dose and sex as an interaction term to test whether observed sex differences in the association between target dose and mortality were statistically significant. We used restricted cubic splines to explore non-linearity in the sexspecific relationship between percentage of target dose and allcause mortality. The number of knots was determined using the Akaike Information Criterion. To account for confounding by
Table 2 Characteristics of all medication prescriptions in the study population

\begin{tabular}{|c|c|c|}
\hline & $\begin{array}{l}\text { Women } \\
(n=1276)\end{array}$ & $\begin{array}{l}\text { Men } \\
(n=1492)\end{array}$ \\
\hline \multicolumn{3}{|c|}{ Medication group, n (\%) } \\
\hline ACEI/ARB & $619(48.5)$ & $724(48.5)$ \\
\hline Beta blocker & $571(44.7)$ & $644(43.2)$ \\
\hline MRA & $86(6.7)$ & $124(8.3)$ \\
\hline \multicolumn{3}{|c|}{ Target dose group, n (\%) } \\
\hline $1 \%-49 \%$ & $564(44.2)$ & $654(43.8)$ \\
\hline $50 \%-99 \%$ & $513(40.2)$ & $608(40.8)$ \\
\hline $100 \%$ or higher & $199(15.6)$ & $230(15.4)$ \\
\hline \multicolumn{3}{|c|}{ Median target dose baseline prescriptions (IQR) } \\
\hline ACEI/ARB & $50(25.0-66.70)$ & $50(25.00-57.10)$ \\
\hline Beta blocker & $25(25.00-50.00)$ & $25(25.00-50.00)$ \\
\hline MRA & $50(50.00-50.00)$ & $50(50.00-50.00)$ \\
\hline
\end{tabular}

ACEI, ACE inhibitor; ARB, angiotensin-receptor blocker; MRA, mineralocorticoid receptor antagonist.

indication, the analyses were inversely weighted with the probability of receiving $\geq 50 \%$ target dose. This probability was calculated as a propensity score. ${ }^{16}$ We calculated propensity scores for each medication group separately, as a patient's dose could differ between medication groups. Missing data on components of the propensity score were imputed with multiple imputation using the mice package ${ }^{17}$ before calculating the propensity scores using the $i p w$ package. ${ }^{18}$ Patients whose EF was not recorded $(7 \%)$ were excluded from HF subtype analyses.

\section{Sensitivity analyses}

We performed two subgroup analyses to test the robustness of our findings across patient subgroups, one including only patients for whom the cardiologist wrote down a diagnosis of HF or decompensatio cordis (HF definition 1) and one redefining $\mathrm{HFpEF}$ as an $\mathrm{EF}$ of $\geq 40 \%$ to include patients with $\mathrm{HF}$ with mid-range EF (HFmrEF). We performed five analyses to test the robustness of our findings across different categorisations of the exposure. The first used exposure categories based on literature ${ }^{11}$; the second used tertiles of the target dose based on the distribution in the cohort; the third used quartiles; and the fourth used the last recorded dosage for each patient with the same exposure groups as the main analysis. As dosage was left-skewed, we used the lowest exposure group as reference for the sensitivity analyses with different exposure categories to obtain more stable estimates. The fifth used binary categories of $\leq 50 \%$ and $>50 \%$ of target dose. To maintain sufficient power, these sensitivity analyses were not stratified by HF subtype.

All analyses were performed in R (R Core Team, Vienna, Austria). A p value of $<0.05$ was considered statistically significant.

\section{RESULTS}

\section{Study population}

Out of the 3811 patients with HF in the CCN database, 1176 patients met our criteria for both de novo $\mathrm{HF}$ and use of $\mathrm{HF}$ medication (figure 1). In total, 934 patients received an ACEI/ ARB; 795 received a beta blocker; and 178 received an MRA (figure 1). Thirty-five per cent of patients with HFrEF had an $\mathrm{EF} \leq 30 \%$.

Women comprised $48 \%$ of the study population and were on average older than men $(71 \pm 12$ vs $67 \pm 12$, respectively). They 


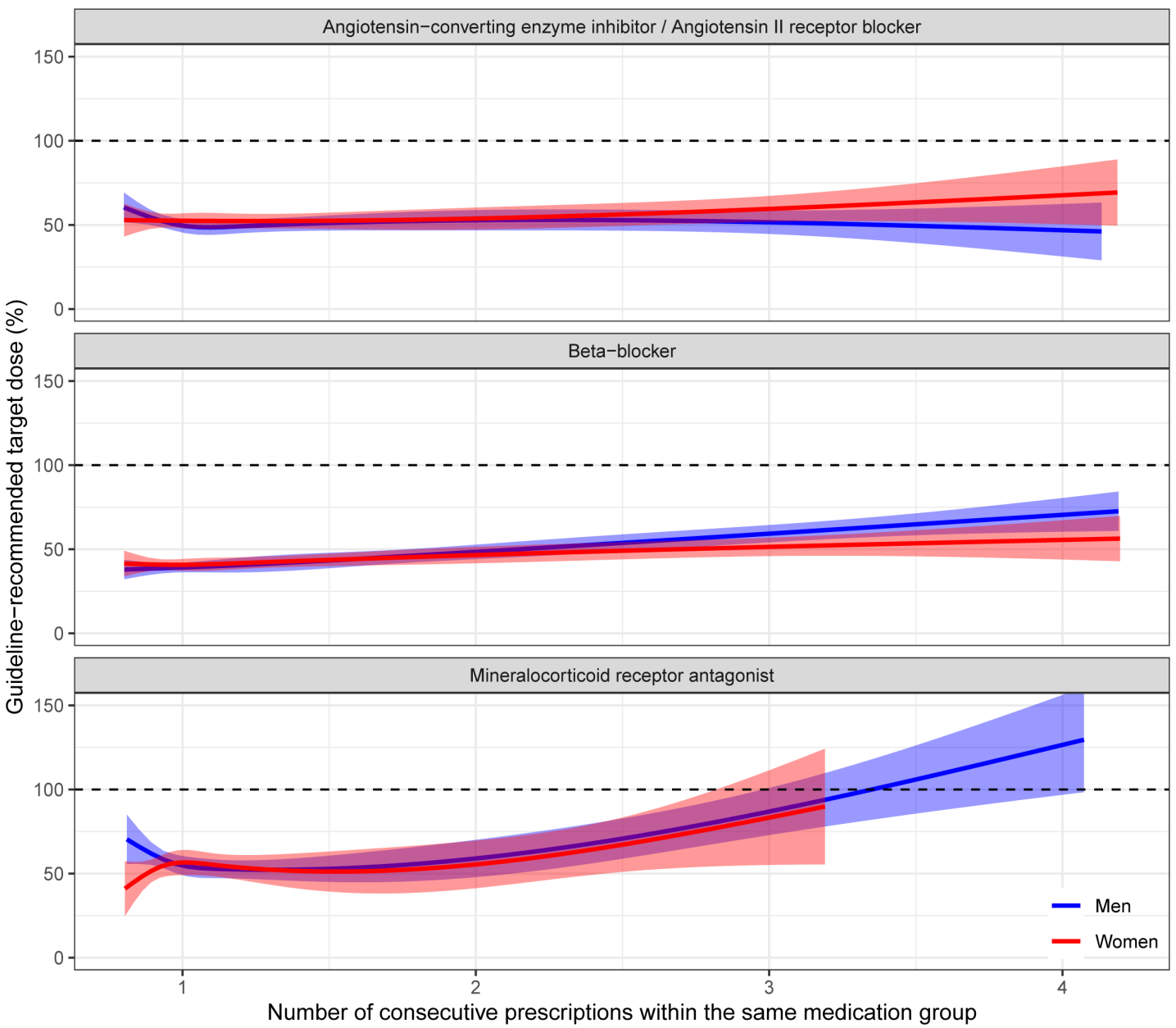

Figure 2 Percentage of target dose across consecutive medication prescriptions.

more often had hypertension (55\% vs $45 \%$ ) and were more often prescribed diuretics $(58 \%$ vs $51 \%)$ than men. However, the prevalence of diabetes ( $13 \%$ vs $20 \%)$, coronary heart disease ( $8 \%$ vs $19 \%)$ and previous coronary interventions ( $8 \%$ vs $23 \%)$ was lower compared with men. Women more often presented with HFpEF (49\% vs 25\%) and less often with HFrEF (29\% vs $47 \%$ ) than men (table 1).

\section{Sex-specific current dosing practice}

At baseline, $76 \%$ of women and $82 \%$ of men received ACEI/ ARBs. These percentages were $68 \%$ and $67 \%$ for beta blockers and $13 \%$ and $17 \%$ for MRAs, respectively (table 1). Over time, the 1176 patients in our cohort received 2768 medication prescriptions (46\% for women) with an average of 1.5 prescriptions per patient. Only $15 \%$ of prescriptions were given at $\geq 100 \%$ target dose in both sexes. The median dose for all three medication categories was similar between the sexes (table 2). Seventy-nine per cent of women vs $86 \%$ of men with HFrEF received ACEI/ARBs, compared with $77 \%$ vs $81 \%$ in HFpEF, respectively. For beta blockers, these percentages were 78\% vs $75 \%$ for $\mathrm{HFrEF}$ and $60 \%$ vs $45 \%$ for $\mathrm{HFpEF}$, respectively (online supplemental table 1).

The natural cubic spline analysis showed that the average dose over consecutive ACEI/ARB and beta-blocker prescriptions remained stable around 50\% of target dose for both sexes, despite some individual patients having dosages of $\geq 100 \%$ target dose. MRA prescriptions had an upward trend in both sexes and reached $100 \%$ after three or four consecutive prescriptions (figure 2).

\section{Relationship between target dose and all-cause mortality}

The median follow-up time was 3.7 years $(2.5-5.9)$ and 252 patients $(48 \%$ women) died during follow-up, with cardiovascular disease being the leading cause of death (49\%). Due to the low number of MRA prescriptions, these were excluded from the survival analyses. Online supplemental table 1 shows the number of women and men included in each analysis. The interaction terms for sex and dose were not statistically significant, and neither were the restricted cubic spline analyses.

\section{ACEls/angiotensin II receptor blockers}

In all patients with HF, the inverse probability-weighted (IPW) mortality risk was similar in the $<50 \%$ target dose group and the reference group (HR=1.01, 95\% CI 0.76 to 1.33 ). The results were the same for women and men (table 3). For HFrEF, the mortality risk was lower in the $<50 \%$ target dose group. This was statistically significant in the whole cohort $(\mathrm{HR}=0.63,95 \%$ CI 0.42 to 0.96 ) and in women ( $\mathrm{HR}=0.49,95 \% \mathrm{CI} 0.25$ to 0.99 ) but not in men (HR $=0.76,95 \%$ CI 0.45 to 1.28 ). For HFpEF, the mortality risk was not significantly different between the $<50 \%$ target dose group and the reference group ( $\mathrm{HR}=1.02$, $95 \%$ CI 0.57 to 1.84 ). The restricted cubic spline suggested women had lower mortality risk at lower doses, whereas men 
Table 3 General and sex-specific HRs for the relationship between percentage of target dose and all-cause mortality stratified by HF subtype

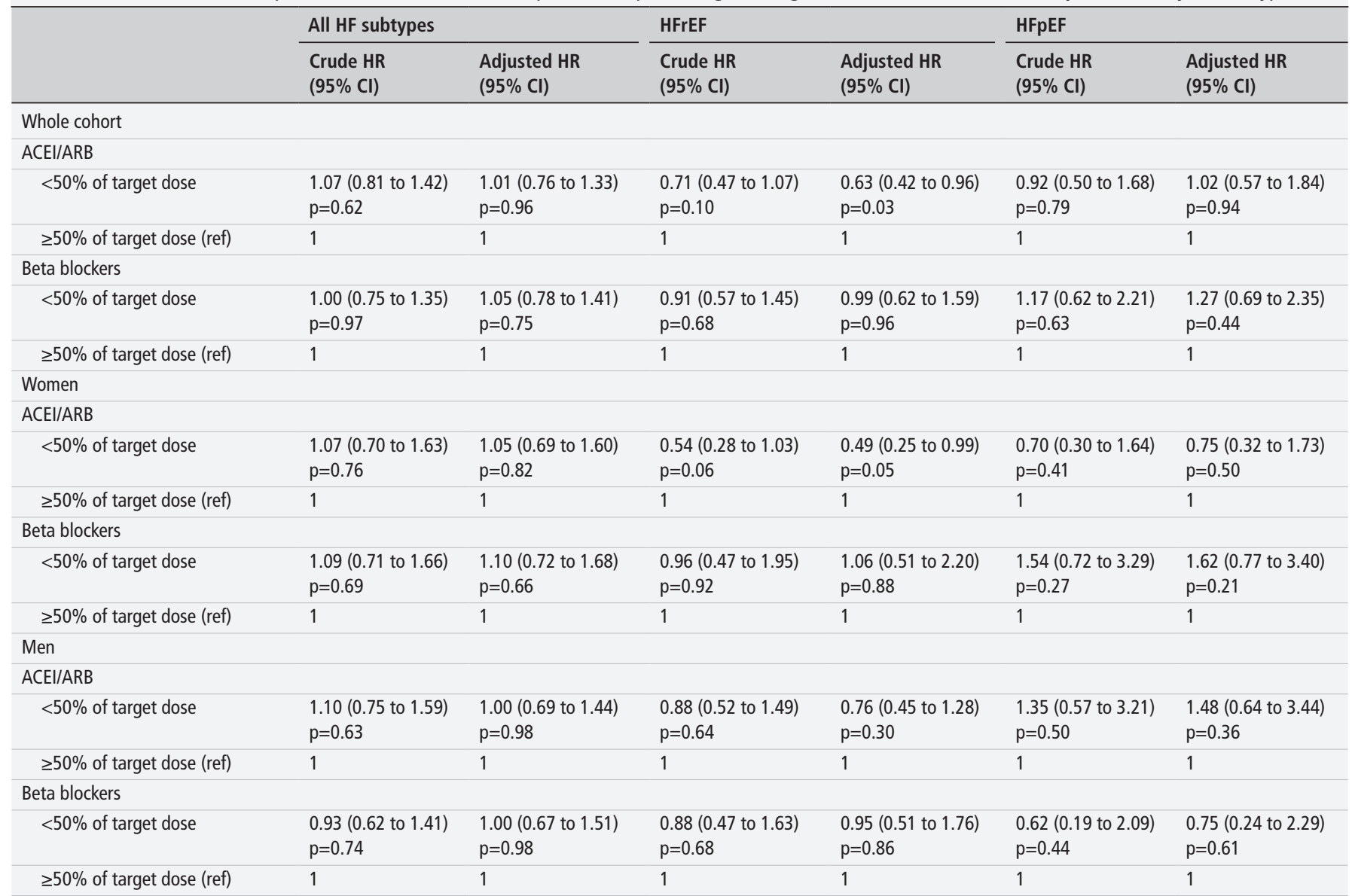

ACEI, ACE inhibitor; AR, angiotensin II receptor; ARB, angiotensin-receptor blocker; HFpEF, heart failure with preserved ejection fraction; HFrEF, heart failure with reduced ejection fraction; ref, reference.

had lower mortality risk at higher doses (figure 3A,C and online supplemental figure $1 \mathrm{~A})$.

\section{Beta blockers}

In all patients with $\mathrm{HF}$, there was no difference in IPW mortality risk between the $<50 \%$ target dose group and the reference group in the whole population $(\mathrm{HR}=1.05,95 \%$ CI 0.78 to 1.41$)$. The sex-stratified results were similar (table 3). There was no association between dosage and allcause mortality in $\mathrm{HFrEF}(\mathrm{HR}=0.99,95 \%$ CI 0.62 to 1.59 ) or in $\operatorname{HFpEF}(\mathrm{HR}=1.27,95 \% \mathrm{CI} 0.69$ to 2.35$)$. The restricted cubic spline suggested women had lower mortality risk at both extremes of the dose spectrum, whereas men had lower mortality risk at intermediate doses (figure 3B,D and online supplemental figure 1B).

\section{Sensitivity analysis}

Performing our analysis in the subgroup of patients with a cardiologist diagnosis of HF or decompensatio cordis $(n=814)$ did not significantly change our results and neither did including HFmrEF patients as HFpEF (online supplemental table 2 and figure 2). The five different target dose categories showed similar results to our main analyses, except for the cohort-based tertiles, which showed a statistically significantly higher mortality risk in the $50 \%-75 \%$ beta-blocker dosage group in the whole cohort $(\mathrm{HR}=1.70,95 \% \mathrm{CI} 1.18$ to 2.44$)$ and women $(\mathrm{HR}=2.25,95 \%$
CI 1.31 to 3.38$)$ but not in men $(\mathrm{HR}=1.29$, 95\% CI 0.78 to 1.21) (online supplemental table 3 ).

\section{DISCUSSION}

The majority of patients with HF in our study received $50 \%$ of the guideline-recommended medication dose. Lower ACEI/ARB dose was associated with the best survival outcomes in women with HFrEF but not men. Beta-blocker dosage was not associated with survival in HFrEF. There was no association between medication dosage and survival in HFpEF (figure 4).

The main strength of our study is the large outpatient population that reflects current practice and covers a wide range of patients with $\mathrm{HF}$ with respect to sex, comorbidities and HF subtype, including patients with mild HF that are not often recruited for studies. ${ }^{19}$ The prevalence of HF in the CCN population is low (3.5\%) and the patients included in our study seem healthier than those in other HF populations as their mortality rate was $21 \%$ over a median follow-up of 3.7 years. This is lower than the 52\% 5-year mortality observed in a population-based cohort from the $\mathrm{UK}^{20}$ and the 17\% 1-year mortality seen across European patients hospitalised for $\mathrm{HF}^{21}$ The main limitation of our study is that data collection and active follow-up were driven by medical need and thus not performed systematically. Despite our efforts to control for indication bias through IPW, residual confounding could have remained and we cannot conclude our observations are causal. Information on medication trajectory was not complete for each patient, so we could not adjust for 

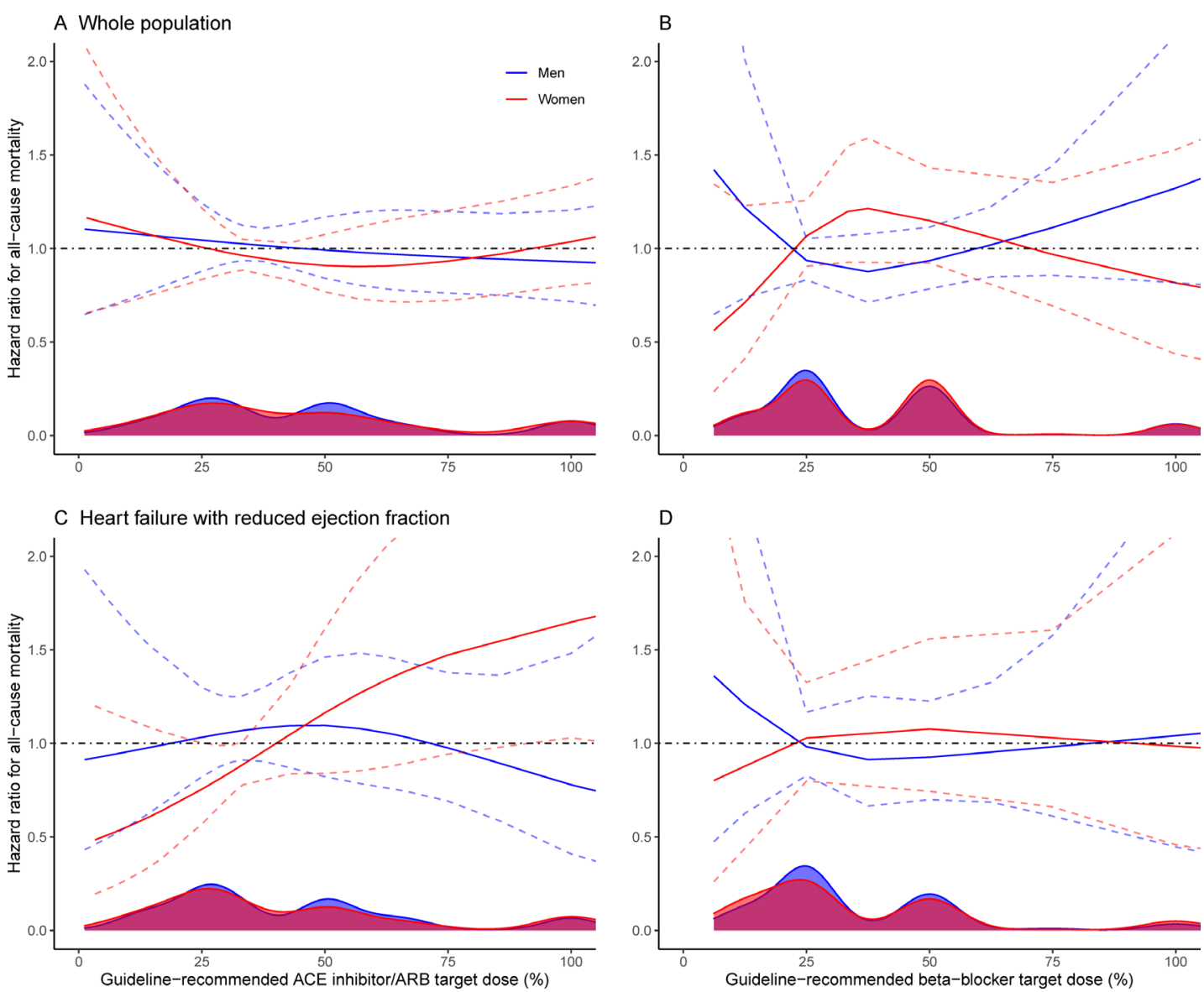

Figure 3 Sex-specific relationship between percentage of target dose and all-cause mortality risk for ACE inhibitors/ARBs in all HF subtypes (A) and HFrEF (C), and beta blockers in all HF subtypes (B) and HFrEF (D). The distribution of percentage of target dose in the population is given by the density plots on the bottom. The coloured solid lines represent the estimated HR across the range of target dose, and the coloured dashed lines represent the $95 \% \mathrm{Cls}$. The black dashed line shows the line of no effect $(\mathrm{HR}=1)$. The cubic spline is by default linear before the first knot, which may be interpreted as no dose (target dose $0 \%$ ) being better than any dose. However, this is an artefact of the cubic spline and thus should not be interpreted as suggesting no dose is better than any dose. ARB, angiotensin-receptor blocker; HF, heart failure; HFrEF, heart failure with reduced ejection fraction.

changes in regimen or evaluate the effect of medication combinations. We excluded patients not receiving medications of interest to reduce risk of bias and thus could not add a 'no-dose' group to our analyses. Sacubitril/valsartan was excluded as it was scarcely prescribed. We did not record HF hospitalisation, quality of life (QoL) and adverse drug reactions (ADRs). Gender was not specifically collected, but we did not observe any differences between women and men in prescription behaviour in our cohort.

We found that women with $\mathrm{HFrEF}$ receiving $<50 \%$ of the guideline-recommended ACEI/ARB target dose had a better prognosis than women receiving higher doses. The cubic spline analysis also suggested women might do better on lower dosages, while men may have a better prognosis on higher dosages, in line with previous findings. ${ }^{11}$ Literature has not identified definite sex differences in pharmacokinetics and pharmacodynamics for ACEI/ARBs, ${ }^{22}$ although pharmacogenomic data suggest the risk of ACEI-specific side effects may be influenced by sex. ${ }^{23}$ Despite this uncertainty about the biological mechanisms underlying our observations, our findings support the hypothesis that sex-specific ACEI/ ARB target doses might benefit patients with HFrEF. Prospective dose-finding trials are needed to determine the exact optimal dosage. Importantly, our findings are based on patients with HF with above-average survival situated between the GP and the hospital and may therefore not be generalisable to patients with more severe HF.

In contrast to previous work, ${ }^{11}$ we did not find an association between beta-blocker dosage and mortality risk in patients with HFrEF. This was surprising because women have a lower distribution volume and slower clearance for this medication, which results in higher beta-blocker blood concentrations compared with men. ${ }^{22}$ These unintentional higher doses may lead to ADRs that negatively affect medication adherence and long-term prognosis, ${ }^{24}$ which advocates for sex-specific dosing. The cubic spline for beta blockers even showed a trend opposite to the previous study, with women doing better at higher doses. This might be an artefact due to the lower sample size or because of residual confounding.

Alternatively, the lack of association between dosage and allcause mortality may be explained by the low prevalence of prior cardiovascular disease and other comorbidities in our population. Data on the effectiveness of guideline-recommended treatment in relatively healthy patients with HF treated by a GP are scarce. ${ }^{19} \mathrm{~A}$ meta-analysis of HF trials showed that treatment with ACEIs, beta blockers and MRAs reduced mortality risk equally for all New York Heart Association classes. ${ }^{25}$ However, the only trial that focused specifically on patients with mild HF (defined here as patients with asymptomatic LV dysfunction) found no difference in all-cause mortality between treatment and placebo. ${ }^{26}$ ACEI treatment did 


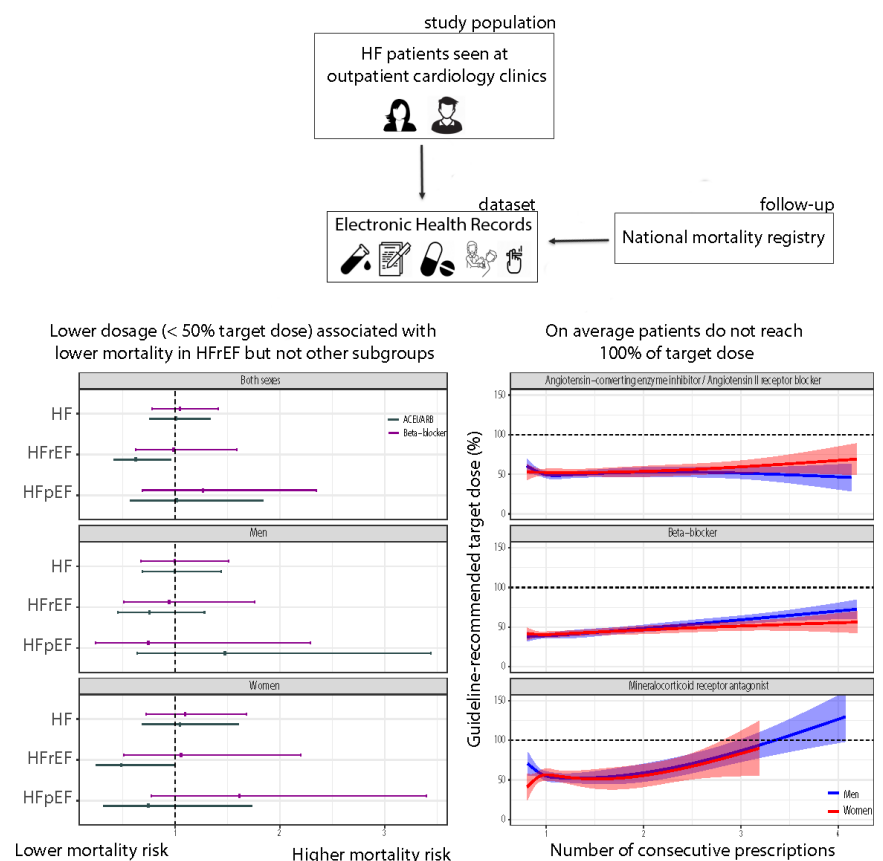

Figure 4 Central figure summarising the design and main findings of this study.

reduce HF-related hospitalisations in those with mild HF and the incidence of $\mathrm{HF}$ in those with reduced EF but no symptoms, ${ }^{26}$ suggesting all-cause mortality might not be the most clinically relevant outcome in our HF population. Future work should include HF hospitalisations and QoL outcomes.

ADRs are an important component of QoL related to medication dosage. ADR risk varies both between women and men and across the spectrum of HF due to inherent biological differences

\section{Key messages}

What is already known on this subject?

$\Rightarrow$ The current 'one-size-fits-all' approach to medication dosage in heart failure (HF) is debated because of known sex differences in drug metabolism and scarcity of sex-specific trial data.

$\Rightarrow$ A recent study based on two heart failure with reduced ejection fraction (HFrEF) cohorts suggested women may reach optimal treatment effect at half of the guidelinerecommended medication dose.

\section{What might this study add?}

$\Rightarrow$ On average, prescriptions for both women and men remained at $50 \%$ of the guideline-recommended target dose for ACE inhibitors (ACEIs)/angiotensin-receptor blockers (ACEI/ARBs) or beta blockers.

$\Rightarrow$ Lower dosage ( $<50 \%$ of target dose) of ACEI/ARBs was associated with better survival in women but not in men with HFrEF. There was no association between beta-blocker dosage and survival in patients with HFrEF of either sex.

$\Rightarrow$ There was no association between medication dosage and survival in patients with HFpEF of either sex.

\section{How might this impact on clinical practice?}

$\Rightarrow$ These results underscore the importance of (re)defining optimal medical therapy for women with HFrEF. and physiological changes that occur as HF progresses. ${ }^{22} 27$ Treating physicians may prefer dosages with lower ADR risk, especially when the benefit of a higher dose is not readily apparent. This may explain why only $15 \%$ of prescriptions in our population were at $\geq 100 \%$ target dose and why ACEI/ARBs and beta blockers were not uptitrated over time. In a previous study, only $25 \%$ of ACEI/ ARB treated patients and 14\% of beta blocker-treated patients reached the target dose after an uptitration phase of 3 months. ${ }^{11}$ Similarly, in a large HFrEF registry, approximately $25 \%$ of ACEI/ $\mathrm{ARB}$ prescriptions and $45 \%$ of beta-blocker prescriptions were given at $<50 \%$ of target dose. ${ }^{12}$ Data on the (sex-specific) relationship between HF medication dosage and ADRs is still scarce, partially due to poor reporting ${ }^{28} 29$ but also because ADRs are rarely recorded in electronic health records. Better quality sexspecific data are needed to evaluate whether ADRs are indeed one of the main reasons for not uptitrating HF medication and whether a sex-specific approach to dosage could alleviate this.

\section{CONCLUSION}

The majority of women and men with HF seen at cardiology outpatient clinics received half of the guideline-recommended medication dose. This dose was associated with improved survival in women with HFrEF for ACEI/ARBs but not for beta blockers. Dose was not associated with survival in patients with HFpEF regardless of sex. These results are not conclusive and underscore the need for dose-finding trials to (re)define optimal medical therapy for women with HFrEF.

\section{Author affiliations}

${ }^{1}$ Laboratory for Experimental Cardiology, Department of Cardiology, University Medical Center Utrecht, Utrecht, The Netherlands

${ }^{2}$ Julius Center for Health Sciences and Primary Care, University Medical Center Utrecht, Utrecht, The Netherlands

${ }^{3}$ Cardiology Centers of the Netherlands, Amsterdam, The Netherlands

${ }^{4}$ Department of Cardiology, University Medical Center Utrecht, Utrecht, The Netherlands

${ }^{5}$ Institute of Cardiovascular Science, Faculty of Popular Health Sciences, University College London, London, UK

${ }^{6}$ Health Data Research UK and Institute of Health Informatics, University College London, London, UK

Correction notice This article has been corrected since it was first published to correct Table 1. The rows were misaligned in the 'Ejection fraction' section; this has now been amended.

Twitter Hester M den Ruijter @InnovatieHester

Acknowledgements Results based on calculations by the authors using nonpublic microdata from Statistics the Netherlands.

Contributors SHB conceived the research question, cleaned the raw data, performed data analyses and wrote the manuscript. NCOM conceived the research question, supported data analysis and critically reviewed the manuscript. IIT and GAS collected the raw data and reviewed the manuscript. PvdH, MJMC and FWA critically reviewed the manuscript. HMdR conceived the research question, obtained funding, supported data analyses and critically reviewed the manuscript. GAS and HMdR are shared last authors.

Funding This work was supported by the Dutch Cardiovascular Alliance consortium DCVA IMPRESS (2020B004) and ERC Consolidator grant UCARE (866478).

Competing interests GAS and IIT are employed by Cardiology Centers of the Netherlands. FWA is supported by UCL Hospitals NIHR Biomedical Research Centre.

Patient consent for publication Not required.

Ethics approval The Cardiology Centers of the Netherlands data were made available under implied consent and transferred to the University Medical Center Utrecht under the Dutch Personal Data Protection Act. This study used data collected during the regular care process and did not subject participants to additional procedures or impose behavioural patterns on them. The medical research ethics committee of the University Medical Center Utrecht declared that the Medical Research Involving Human Subjects Act does not apply to this study (proposal number 17/359). 
Provenance and peer review Not commissioned; externally peer reviewed.

Data availability statement Data are not available. The Cardiology Centers of the Netherlands database cannot be shared outside the University Medical Center Utrecht's infrastructure because of ethical constraints. The data obtained from Statistics Netherlands are project-specific and cannot be accessed by unregistered researchers.

Supplemental material This content has been supplied by the author(s). It has not been vetted by BMJ Publishing Group Limited (BMJ) and may not have been peer-reviewed. Any opinions or recommendations discussed are solely those of the author(s) and are not endorsed by BMJ. BMJ disclaims all liability and responsibility arising from any reliance placed on the content. Where the content includes any translated material, BMJ does not warrant the accuracy and reliability of the translations (including but not limited to local regulations, clinical guidelines, terminology, drug names and drug dosages), and is not responsible for any error and/or omissions arising from translation and adaptation or otherwise.

Open access This is an open access article distributed in accordance with the Creative Commons Attribution Non Commercial (CC BY-NC 4.0) license, which permits others to distribute, remix, adapt, build upon this work non-commercially, and license their derivative works on different terms, provided the original work is properly cited, appropriate credit is given, any changes made indicated, and the use is non-commercial. See: http://creativecommons.org/licenses/by-nc/4.0/.

ORCID iDs

Sophie Heleen Bots http://orcid.org/0000-0002-4483-5582

Hester M den Ruijter http://orcid.org/0000-0001-9762-014X

\section{REFERENCES}

1 Savarese G, Lund LH. Global public health burden of heart failure. Card Fail Rev 2017:3:7-11.

2 Scott PE, Unger EF, Jenkins MR, et al. Participation of Women in Clinical Trials Supporting FDA Approval of Cardiovascular Drugs. J Am Coll Cardiol 2018;71:1960-9.

3 Dunlay SM, Roger VL, Redfield MM. Epidemiology of heart failure with preserved ejection fraction. Nat Rev Cardiol 2017;14:591-602.

4 Soldin OP, Mattison DR. Sex differences in pharmacokinetics and pharmacodynamics. Clin Pharmacokinet 2009;48:143-57.

5 Ponikowski P, Voors AA, Anker SD, et al. 2016 ESC Guidelines for the diagnosis and treatment of acute and chronic heart failure: The Task Force for the diagnosis and treatment of acute and chronic heart failure of the European Society of Cardiology (ESC)Developed with the special contribution of the Heart Failure Association (HFA) of the ESC. Eur Heart I 2016;37:2129-200.

6 Pilote L, Raparelli V. Participation of women in clinical trials: not yet time to rest on our laurels. J Am Coll Cardiol 2018;71:1970-2.

7 Dunlay SM, Roger VL, Redfield MM. Epidemiology of heart failure with preserved ejection fraction. Nat Rev Cardiol 2017;14:591-602.

8 Harada E, Mizuno Y, Kugimiya F, et al. Plasma levels of BNP are lower in women than men among patients with HFpEF. J Card Fail 2017;23:S58.

9 Sobhani K, Nieves Castro DK, Fu Q, et al. Sex differences in ischemic heart disease and heart failure biomarkers. Biol Sex Differ 2018;9:43.

10 Sharpe N. Clinical trials and the real world: selection bias and generalisability of trial results. Cardiovasc Drugs Ther 2002;16:75-7.
11 Santema BT, Ouwerkerk W, Tromp J, et al. Identifying optimal doses of heart failure medications in men compared with women: a prospective, observational, cohort study. Lancet 2019;394:1254-63.

12 Veenis JF, Rocca H-PB-L, Linssen GC, et al. Impact of sex-specific target dose in chronic heart failure patients with reduced ejection fraction. Eur J Prev Cardiol 2020;2 047487320923185:2047487320923185.

13 McMurray JJV, Packer M, Desai AS, et al. Dual angiotensin receptor and neprilysin inhibition as an alternative to angiotensin-converting enzyme inhibition in patients with chronic systolic heart failure: rationale for and design of the prospective comparison of ARNI with ACEl to determine impact on global mortality and morbidity in heart failure trial (PARADIGM-HF). Eur I Heart Fail 2013;15:1062-73.

14 McMurray JJV, Packer M, Desai AS, et al. Angiotensin-neprilysin inhibition versus enalapril in heart failure. N Eng/ J Med 2014;371:993-1004.

15 Shalansky K, RSunderji R, Loewen P. Drug and therapeutics Newsletter. CSU Pharmaceutical Sciences 2004;11.

16 Elze MC, Gregson J, Baber U, et al. Comparison of propensity score methods and covariate adjustment: evaluation in 4 cardiovascular studies. J Am Coll Cardiol 2017:69:345-57.

17 Sv B, Groothuis-Oudshoorn K. Mice: multivariate imputation by chained equations in R. J Stat Softw 2010:1-68.

18 van der Wal WM, Geskus RB. ipw: an R package for inverse probability weighting 2011;43:23.

19 Gollop ND, Ford J, Mackeith P, et al. Are patients in heart failure trials representative of primary care populations? A systematic review. BJGP Open 2018;2:bjgpopen18X101337.

20 Taylor CJ, Ordóñez-Mena JM, Roalfe AK, et al. Trends in survival after a diagnosis of heart failure in the United Kingdom 2000-2017: population based cohort study. BMJ 2019:364:1223.

21 Maggioni AP, Dahlström U, Filippatos G, et al. EURObservational research programme: regional differences and 1-year follow-up results of the heart failure pilot survey (ESCHF pilot). Eur J Heart Fail 2013;15:808-17.

22 Rosano GMC, Lewis B, Agewall S, et al. Gender differences in the effect of cardiovascular drugs: a position document of the Working group on pharmacology and drug therapy of the ESC. Eur Heart J 2015;36:2677-80.

23 Mas S, Gassò P, Alvarez S, et al. Pharmacogenetic predictors of angiotensin-converting enzyme inhibitor-induced cough: the role of ACE, ABO, and BDKRB2 genes. Pharmacogenet Genomics 2011:21:531-8.

24 Leporini C, De Sarro G, Russo E. Adherence to therapy and adverse drug reactions: is there a link? Expert Opin Drug Saf 2014;13(Suppl 1):41-55.

25 Miller RJH, Howlett JG, Exner DV, et al. Baseline functional class and therapeutic efficacy of common heart failure interventions: a systematic review and meta-analysis. Can J Cardiol 2015;31:792-9.

26 SOLVD Investigators. Effect of enalapril on mortality and the development of heart failure in asymptomatic patients with reduced left ventricular ejection fractions. $N$ Engl J Med 1992;327:685-91.

27 Lainscak M, Vitale C, Seferovic P, et al. Pharmacokinetics and pharmacodynamics of cardiovascular drugs in chronic heart failure. Int I Cardiol 2016;224:191-8.

28 Bots SH, den Ruijter HM. Recommended heart failure medications and adverse drug reactions in women. Circulation 2019;139:1469-71.

29 Bots SH, Groepenhoff F, Eikendal ALM, et al. Adverse Drug Reactions to GuidelineRecommended Heart Failure Drugs in Women: A Systematic Review of the Literature. JACC Heart Fail 2019:7:258-66. 


\section{Correction: Heart failure medication dosage and survival in women and men seen at outpatient clinics}

Bots SH, Onland-Moret NC, Tulevski II, et al. Heart failure medication dosage and survival in women and men seen at outpatient clinics. Heart 2021;107:1748-55.

This article has been corrected since it was first published to correct. The rows were misaligned in the 'Ejection fraction' section; please see below for the corrected portion of the table.

\begin{tabular}{lrc}
\hline & Women & Men \\
\hline Ejection fraction $(n, \%)$ & $162(28.9)$ & \\
\hline$<40 \%$ & $81(15.3)$ & $291(47.3)$ \\
\hline $40 \%-49 \%$ & $272(48.5)$ & $123(20.0)$ \\
\hline$>50 \%$ & $41(7.3)$ & $155(25.2)$ \\
\hline Not recorded & & $46(7.5)$ \\
\hline & & \\
& &
\end{tabular}

Open access This is an open access article distributed in accordance with the Creative Commons Attribution Non Commercial (CC BY-NC 4.0) license, which permits others to distribute, remix, adapt, build upon this work non-commercially, and license their derivative works on different terms, provided the original work is properly cited, appropriate credit is given, any changes made indicated, and the use is non-commercial. See: http://creativecommons.org/licenses/by-nc/4.0/.

(c) Author(s) (or their employer(s)) 2022. Re-use permitted under CC BY-NC. No commercial re-use. See rights and permissions. Published by BMJ.

Heart 2022;108:e4. doi:10.1136/heartjnl-2021-319229corr1

Check for updates 